\title{
Review
}

\section{Current understanding of TRPM7 pharmacology and drug development for stroke}

\author{
Christine You Jin BAE, Hong-shuo SUN* \\ Departments of Surgery, Physiology, and Pharmacology, Institute of Medical Science, Faculty of Medicine, University of Toronto, \\ Toronto, Ontario, Canada M5S 1 A8
}

\begin{abstract}
The initial excitement and countles efforts to find a pharmacological agent that disrupts the excitotoxic pathway of ischemic neuronal death have only led to disappointing clinical trials. Currently, a thrombolytic agent called recombinant tissue plasminogen activator (rt$\mathrm{PA}$ ) is the only pharmacological treatment available for patients with acute ischemic stroke in most countries. Even though its efficacy has been confirmed repeatedly, rt-PA is considerably underused due to reasons including a short therapeutic window and repeated complications associated with its use. A search for alternative mechanisms that may operate dependently or independently with the well-established excitotoxic mechanism has led researchers to the discovery of newly described non-glutamate mechanisms. Among the latter, transient receptor potential melastatin 7 (TRPM7) is one of the important nonglutamate mechanisms in stroke, which has been evaluated in both in-vitro and in-vivo. In this review, we will discuss the current state of pharmacological treatments of ischemic stroke and provide evidence that TRPM7 is a promising therapeutic target of stroke.
\end{abstract}

Keywords: ion channels; TRPM7; cerebral ischemia; stroke; neuroprotection; recombinant tissue plasminogen activator (rt-PA); glutamate receptors

Acta Pharmacologica Sinica (2013) 34: 10-16; doi: 10.1038/aps.2012.94; published online 23 Jul 2012

\section{Introduction}

Stroke is one of the most common causes of death and a leading cause of disability worldwide ${ }^{[1,2]}$. The burden of stroke on stroke survivors, their family members and society as a whole is unquestionably immense. The mean lifetime cost of stroke per person in the United States is estimated to be $\$ 103,576$ in 1990, which was an averaged estimate across all stroke subtypes $^{[3]}$. The socioeconomic burden to meet the costs of managing stroke is expected to further increase largely due to our aging population. From 2005 to 2050, the direct and indirect costs of ischemic stroke alone in the United States is projected to exceed $\$ 2.2$ trillion $^{[4]}$. The most effective way of alleviating the burden of stroke is primary prevention. Hence, high-risk or stroke-prone individuals should aim to reduce modifiable risk factors of stroke, which are well documented in a guideline from the American Heart Association ${ }^{[2]}$.

A stroke can be classified as either ischemic or hemorrhagic stroke. Ischemic stroke arises from an occlusion of a major cerebral artery (commonly the middle cerebral artery) by thrombosis or embolism, whereas hemorrhagic stroke arises

\footnotetext{
* To whom correspondence should be addressed.

E-mail hss.sun@utoronto.ca

Received 2012-04-04 Accepted 2012-06-12
}

from a rupturing of a blood vessel. The ischemic stroke is about 10-times more frequent than hemorrhagic stroke in Western countries ${ }^{[5]}$.

Although compromised blood flow during ischemic stroke has detrimental effects on the entire neurovascular unit, neurons are particularly vulnerable to injury and even death due to their high metabolic demand and electrical excitability. With the use of quantitative neurostereology and stroke neuroimaging, Saver et al ${ }^{[6]}$ estimated that a typical untreated large vessel ischemic stroke will result in losses of 120 million neurons, 830 billion synapses, and $714 \mathrm{~km}$ of myelinated fibers in each hour. These abrupt neuronal losses that occur during $1 \mathrm{~h}$ of untreated ischemia normally take 3.6 years to occur in a healthy aging brain. Such estimates highlight the importance of urgent stroke care once ischemia begins.

Over the past decades, much attention has been given to developing effective pharmacological treatments that can be administered immediately after acute ischemic insults to minimize cerebral damage. Contrary to initial expectations and the early promising results gained from animal stroke models, an overwhelming number of attempts to treat ischemia pharmacologically has failed to translate into clinical treatments. The only drug that is currently approved in most countries for clinical use is a recombinant tissue plasminogen activa- 
tor (rt-PA, alteplase), which relieves occlusion by dissolving clots $^{[7,8]}$. Although it has proven to be clinically effective, the usage is limited by several reasons that will be explained in the next section. Therefore, there is still a pressing need to develop new effective treatments for stroke. In this review, we will focus on the current situation with the acute pharmacological treatment of stroke. Then, for the remaining part of the review, we will discuss the potential clinical benefits that could be gained by targeting the TRPM7 (Transient Receptor Potential Melastatin 7) channel, a recently discovered non-glutamate mechanism shown to be involved in ischemic damage, during cerebral ischemia.

\section{Pharmacological approach}

Traditionally, pharmacological agents for treating ischemic stroke have been broadly classified into two groups: thrombolytics and neuroprotectants ${ }^{[9-11]}$. Thrombolytics are compounds that act to restore blood flow by dissolving blood clots, while neuroprotectants are compounds that are designed to interfere with the biochemical events in the ischemic cascade and thereby lessening neuronal damage.

\section{Thrombolytic agents}

At present, recombinant tissue plasminogen activator (rt-PA, alteplase), the thrombolytic agent, is the only drug approved by Food and Drug Administration (FDA) for clinical use, and proven to be the only effective intervention available for early management of ischemic stroke $\mathrm{e}^{[7,8]}$. The original study done by the National Institute of Neurological Disorders and Stroke $(\mathrm{NINDS})^{[12]}$ reported that when rt-PA is given intravenously within the first $3 \mathrm{~h}$ after the onset of symptoms, there was an absolute increase in favourable outcome by $11 \%-13 \%$ at 3 months as compared with placebo group.

However, rt-PA is not without shortcomings. Despite its proven efficacy, it is estimated that less than $2 \%$ patients receive rt-PA primarily due to inability to meet its short 3-h therapeutic window ${ }^{[13]}$. Although the initial 3-h therapeutic window has been expanded to $4.5 \mathrm{~h}^{[8,14]}$, the earliest possible administration is still highly recommended to maximize the benefit, while minimizing adverse complications. Often, a poor understanding of stroke symptoms by stroke victims and/or their family members delay the time of hospital admission after onset ${ }^{[15]}$. Upon hospital admission, administration of rt-PA is further delayed when a computed tomography scan is done to exclude patients with a brain hemorrhage or major infarction. This step inevitably limits more eligible patients from receiving the treatment. Rt-PA administration in patients with acute ischemic stroke is also more frequently associated with symptomatic intracranial hemorrhage though it is still 10 times more likely to benefit than to harm eligible patients with acute ischemic stroke ${ }^{[16]}$. Unlike its beneficial effect in the intravascular space by acting as a thrombolytic enzyme, emerging evidence also suggests that rt-PA in the extravascular space lead to the development of edema and excitotoxic cell death. Both beneficial and deleterious effects of rt-PA are thoroughly reviewed by Yepes et $a l^{[11]}$.

\section{Neuroprotectants}

Aside from thrombolytics that aid reperfusion of blood flow in an ischemic area, researchers have been seeking ways to screen and/or develop neuroprotectants that protect neurons by interfering with ischemic cascades triggered by acute ischemic episodes. With expanding knowledge of the molecular pathways leading to ischemic neuronal damage, more than 1000 experimental drugs have been evaluated for the neuroprotective effects over the years, but all failed to translate bench findings to the patient bed ${ }^{[17]}$. Until recently, finding a way to disrupt the glutamatergic mechanism has been the key aim in neuroprotective research. Although the contribution of excitotoxic-cascade in ischemic injuries is well established and unquestionable, the repeated failure of clinical trials suggest that solely targeting excitotoxic cascade is not sufficient. Increasingly more attention has been given to finding other novel processes that may either work independently or jointly with glutamate pathways. Some of the channels involved in the non-glutamate mechanisms include (Figure 1A): transient receptor potential (TRP) channels ${ }^{[18-22]}$, acid-sensing ion channels ${ }^{[23-25]}$, volume-regulated anion channels ${ }^{[26]}$, hemichannels ${ }^{[27-29]}$, ATP-sensitive potassium channels ${ }^{[30-32]}$, sodiumcalcium exchangers ${ }^{[33-35]}$ and non-selective cation channels ${ }^{[36]}$.

\section{Glutamate receptors: traditional, most sought-out therapeutic target}

The glutamate-mediated excitotoxic mechanism (Figure 1A) is the most extensively studied pathway in the context of ischemic neurodegeneration. Consequently, developing neuroprotectants that may interfere with glutamatergic signaling has been the focus of the early neuroprotection research. Following the early anoxic depolarization due to the failures of energy-dependent pumps, a massive release of glutamate in conjunction with the impairment (or reversal) of reuptake mechanisms result in accumulation of extracellular glutamate. This over-activates glutamate receptors, NMDAR (N-methyl$D$-aspartic acid receptor) and AMPAR (DL-a-amino-3hydroxy-5-methyl-4-isoxazole propionic acid receptor), and causes excessive $\mathrm{Ca}^{2+}$ overload, triggering $\mathrm{Ca}^{2+}$ mediated harmful activation of enzymes, free radical formation and eventual cell death ${ }^{[37,38]}$. In order to interrupt this toxic $\mathrm{Ca}^{2+}$ influx, various glutamate receptor antagonists were tested in rodents but failed to demonstrate efficacy in clinical trials ${ }^{[10]}$

One suggested explanation for repeated disappointing outcomes is that pathological glutamate release takes place too early in the ischemic cascade and antagonizing glutamate receptors in time may not be attainable in clinical settings. Most currently tested NMDAR antagonists have a very short therapeutic window following the onset of ischemia. For example, MK-801, which is a non-competitive antagonist for NMDARs, offers a neuroprotective effect only when given 30 min after the onset of ischemia ${ }^{[39]}$, and dextrorphan, which is another noncompetitive NMDAR antagonist, also has a short therapeutic window of $2 \mathrm{~h}^{[40]}$.

Furthermore, contrary to the simple traditional view that only focused on the destructive effects of NMDARs upon 
A

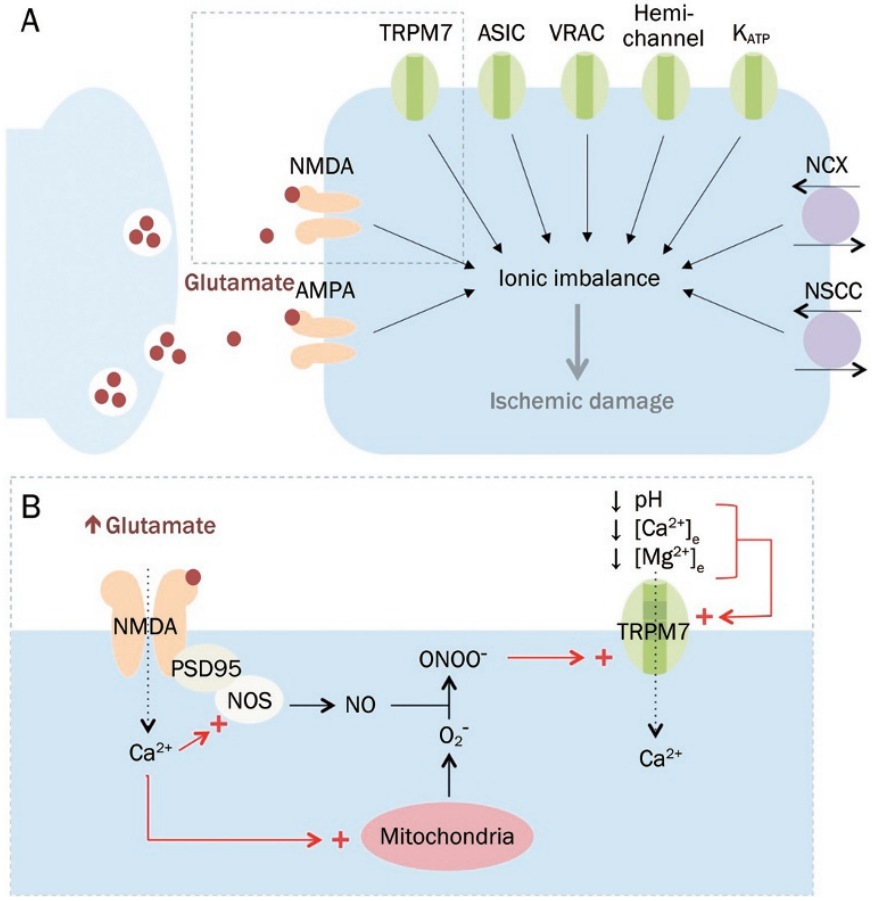

Figure 1. (A) Schematic diagram of molecular pathways during ischemia including the traditional glutamate dependent mechanism and newly discovered non-glutamate dependent mechanisms. Glutamate dependent mechanism of cerebral ischemia is the most extensively studied mechanism and it is thought that energy failure due to ischemia leads to depolarization of presynaptic neurons, which leads to a massive release of glutamate. Increased glutamate in the extracellular space hyper-activates glutamate receptors, which consequently leads to excitotoxic $\mathrm{Ca}^{2+}$ overload. Recently, other non-glutamate dependent mechanisms that may contribute to the overall ionic imbalance have been discovered and these are: TRPM7, ASICs, VRACs, hemichannels, $\mathrm{K}_{\text {ATP }}$ NCXs, and NSCCs. These pathways may even interact with each other suggesting complex molecular cascades upon ischemic insults. (B) Current working model of TRPM7 activation during cerebral Ischemia. Ischemic conditions are associated with decreases in extracellular $\mathrm{pH}$ (acidic) and concentrations of divalent ions $\left(\mathrm{Ca}^{2+}\right.$ and $\left.\mathrm{Mg}^{2+}\right)$ and these changes may activate TRPM7 independent of other pathways. The initial influx of $\mathrm{Ca}^{2+}$ via glutamate-dependent pathway stimulates productions of nitrogen oxide $(\mathrm{NO})$ and superoxide $\left(\mathrm{O}_{2}{ }^{-}\right)$ and these combine to produce peroxynitrite $\left(\mathrm{ONOO}^{-}\right)$. These reactive oxygen species and reactive nitrogen species (ROS and RNS) further promote sustained activation of TRPM7, which consequently causes a prolonged build up of intracellular $\mathrm{Ca}^{2+}$ leading to ischemic damages.

ischemic activation, it was recently revealed that depending on the subcellular pools, activation of NMDARs could either be beneficial or deleterious ${ }^{[41]}$. Even though NMDARs get trafficked to synapses continuously, a substantial proportion of them remain as extrasynaptic receptors. Stimulation of synaptic NMDARs leads to well-tolerated $\mathrm{Ca}^{2+}$ influx that triggers downstream cascades that makes neurons more resistant to ischemic insults. Comparable stimulation of extrasynaptic NMDARs, on the other hand, initiates cell death pathways. These opposing effects of synaptic and extrasynaptic NMDARs may explain the disappointing results of previous neuroprotectants that tend to antagonize all NMDARs, regardless of their subcellular localizations and respective downstream signaling cascades.

Another major setback that led to discontinuation of clinical trial for most glutamate antagonists, both competitive and noncompetitive, was a similar pattern of side effects that were presented in patients, regardless of the pharmacology of drugs ${ }^{[42]}$. These symptoms tended to be neurological in nature: changes in sensory perception, dysphoria, hypertension, disorientation, heightened agitation, paranoia, hallucination, and even catatonia at higher doses.

Hence, a new therapeutic approach targeting the glutamate excitotoxic pathway should aim to block only the NMDARs that are linked to neurotoxicity with minimal (or tolerable) side effects. This goal could also be met by developing drugs that can disturb downstream targets of NMDARs ${ }^{[43-45]}$, or drugs that target the non-glutamate mechanisms. Blocking NMDARs may not have been sufficient in clinical situations because there seem to be other newly discovered nonglutamate mechanisms that contribute to ischemic neuronal cell death during stroke (see review ${ }^{[46]}$ ). Among many of these promising targets in ischemic neurodegeneration (Figure 1A), TRPM7 will be the focus of remaining parts.

\section{TRPM7: Newly discovered, promising therapeutic target}

TRPM7 is the seventh member in the melastatin subfamily of TRP channels ${ }^{[4]}$. It is a ubiquitously expressed $\mathrm{Ca}^{2+}$ permeable non-selective cation channel that is permeable to monovalent and most divalent cations with the selectivity profile in a sequence of ${ }^{[48]}: \mathrm{Zn}^{2+} \approx \mathrm{Ni}^{2+}>>\mathrm{Ba}^{2+}>\mathrm{Co}^{2+}>\mathrm{Mg}^{2+} \geq \mathrm{Mn}^{2+} \geq \mathrm{Sr}^{2+} \geq$ $\mathrm{Cd}^{2+} \geq \mathrm{Ca}^{2+}$. TRPM7 is unique in that it possesses the atypical serine/threonine protein kinase domain at the C-terminus ${ }^{[49]}$. Binding of $\mathrm{Mg}^{2+}$-nucleotides to this kinase domain is suggested to be important for the tonic inhibition of constitutively active TRPM7 $7^{[50]}$. Though this functional enzymatic domain is homologous to a family of alpha-kinases ${ }^{[49]}$, there is a very limited understanding of its substrates and associated physiological functions. It has been proposed that TRPM7 kinase phosphorylates a conserved serine residue $\left(\mathrm{Ser}^{5}\right)$ in N-terminus of annexin $1^{[51]}$. This phosphorylation may modulate the activity of annexin 1 as this region is important for interacting with other proteins and membranes, but further investigation is required to determine the functional significance of phosphorylating annexin 1. TRPM7 kinase also seems to phosphorylate myosin IIA, IIB, and IIC, which in turn affects actomyosin contractility and cell adhesion ${ }^{[52,53]}$. However, no study has shown the involvement of the kinase domain in neuronal injury during stroke. Under physiological conditions, it has been repeatedly suggested that TRPM7 has a critical role in cell survival and proliferation ${ }^{[54-56]}$. Tight regulation of TRPM7 expression seems to be the key as both deletion ${ }^{[54,55]}$ and overexpression of the gene ${ }^{[57]}$ lead to cell death. Although TRPM7 is constitutively active ${ }^{[48,58]}$, its activities seem to be modulated by various factors, including the ones that normally occur during ischemic stroke. For instance, TRPM7 activity is potentiated by oxidative stress ${ }^{[59]}$ and reductions in extracellular $\mathrm{pH}$ 
(acidic) ${ }^{[60,61]}$, extracellular concentrations of $\mathrm{Ca}^{2+}$ and $\mathrm{Mg}^{2+}$. In line with these properties, several lines of evidence convincingly suggest that activation of TRPM7 during ischemic condition is a glutamate excitotoxicity-independent pathway that significantly contributes to the pathological $\mathrm{Ca}^{2+}$ overload. The first evidence of the role of TRPM7 channels in cerebral ischemia came from an in vitro study using an oxygen-glucose deprivation (OGD) model in cultured primary cortical neurons ${ }^{[22]}$. Compared to the control, neurons that were transfected with siRNA targeting TRPM7 showed inhibition of its characteristic outward rectifying current, and decreases in ROS production, radiolabeled $\mathrm{Ca}^{2+}$ influx, and cell death. More interestingly, these neuroprotective effects observed with TRPM7 knockdown remained for a longer period of time than pharmacologically antagonizing the widely accepted contributors (eg glutamate NMDA and AMPA receptor and L-type calcium channels) of excitotoxicity, suggesting that TRPM7 has an independent role in OGD-mediated cell death and targeting TRPM7 may have a longer treatment window. More recently, in vivo data further confirmed the role of TRPM7 in mediating ischemic neuronal cell death ${ }^{[21]}$. When TRPM7 channels in hippocampal CA1 neurons of adult rat brains were suppressed by injecting viral vectors containing a small hairpin RNA (shRNA) sequence targeting TRPM7, neurons showed no signs of adverse effects on cell survival, neuronal and dendritic morphology, or synaptic plasticity. When these rats were subjected to $15 \mathrm{~min}$ of global ischemia, TRPM7 suppression rendered neurons more resilient to neuronal death, preserved normal morphological integrity and enhanced functional outcomes, which were exemplified by behavioural tests such as fear-associated and spatial-navigation memory tasks. Such findings confirm the pathological roles of TRPM7 in ischemic neuronal damages, and suggest it as a promising therapeutic target that could be better tolerated when acutely blocked and offer a different therapeutic window than targeting the traditional NMDAR-mediated glutamatergic pathway.

According to the current working model of TRPM7 activation during cerebral ischemia (Figure 1B), conditions associated with cerebral ischemia, such as reduction in extracellular $\mathrm{Ca}^{2+}$ and $\mathrm{Mg}^{2+}$ concentrations and decrease in $\mathrm{pH}$, activate TRPM7. The initial rise in intracellular $\mathrm{Ca}^{2+}$ through NMDARs stimulates formation of reactive oxygen and nitrogen species (ROS and RNS), and these products feedback to TRPM7 and further activates TRPM7. The latter activation mechanism with ROS and RNS makes the role of TRPM7 more substantial and clinically relevant since it creates self-sustaining positive feedback loop. Consequently, even with glutamatergic channel antagonism, the intracellular $\mathrm{Ca}^{2+}$ accumulation during ischemia may be prolonged via TRPM7.

\section{Developing potential TRPM7 blocker}

Although more thorough investigations on molecular mechanisms of TRPM7 in the context of ischemic stroke should be done before validating it as a therapeutic target, one of the current issues with TRPM7 research is not having a selective pharmacological inhibitor ${ }^{[4]}$. Currently, some non-selective inhibitors are used to assist the understanding of its role in physiological and pathological conditions. These include: trivalent ions, such as $\mathrm{Gd}^{3+}\left(\left(\mathrm{IC}_{50} \sim 1.4-2.5 \mu \mathrm{mol} / \mathrm{L}\right)\right.$ and $\mathrm{La}^{3}\left(\mathrm{IC}_{50}\right.$ $\sim 17 \mu \mathrm{mol} / \mathrm{L})^{[22,}$, 22$], 2$-aminoethoxydiphenyl borate (2-APB) $\left(\mathrm{IC}_{50} \sim 50 \mu \mathrm{mol} / \mathrm{L}\right)^{[63]}$, NDGA (nordihydroguaiaretic acid, $\mathrm{IC}_{50}$ $\sim 6.3 \mu \mathrm{mol} / \mathrm{L})^{[64]}, \mathrm{AA} 861\left(\mathrm{IC}_{50} \sim 6.0 \mu \mathrm{mol} / \mathrm{L}\right)^{[64]}, \mathrm{MK} 886\left(\mathrm{IC}_{50}\right.$ $\sim 8.6 \mu \mathrm{mol} / \mathrm{L})^{[64]}$ and carvacrol $\left(\mathrm{IC}_{50} \sim 307 \mu \mathrm{mol} / \mathrm{L}\right)^{[65]}$. Among these non-selective TRPM7 blockers, a group of 5-lipoxygenase inhibitors (5-LOX), NDGA, AA861, and MK886, showed potent effects on blocking TRPM7 whole-cell current in TRPM7 overexpressing HEK293 cells without affecting the TRPM7 protein expression ${ }^{[64]}$. These blockers also efficiently reduced the characteristic cell rounding that normally occurs with overexpressing TRPM7 in HEK293 providing another line of evidence that these blockers have an inhibitory effect on TRPM7. In contrast, other 5-LOX inhibitors, 5,6-dehydroarachidonic acid $(5 \mu \mathrm{mol} / \mathrm{L})$ and zileuton $(50 \mu \mathrm{mol} / \mathrm{L})$ did not affect the channel activity and was unable to prevent TRPM7-mediated cell rounding, suggesting that these inhibitory effects of NDGA, AA861, and MK886 on TRPM7 are independent of their actions on 5-lipoxygenase. This independency was further confirmed when addition of 5-lipoxygenase products, leukotriene B4 and leukotriene D4, did not stimulate channel activities of TRPM7. Carvacrol, a predominant part of the essential oils found in herbs, suppressed constitutively active TRPM7 current in a concentration-dependent manner only in TRPM7-transfected HEK293 cells and not in mock transfect HEK293 cells. Furthermore, the action of carvacrol was also shown to be sufficient to block TRPM7-dependent transmitter release in CA3-CA1 hippocampal neurons overexpressing TRPM7 channels, which is a functional role of TRPM7 that has previously been observed in cholinergic sympathetic neurons ${ }^{[66]}$. In the same study ${ }^{[65]}$, drosophila TRPL, which belongs to the TRPC subfamily, was also inhibited by carvacrol. Other than inhibiting TRPM7 and TRPC, carvacrol has shown to activate thermoTRPs, TRPV3, and TRPA1 in earlier study ${ }^{[6]]}$. At present, the mechanisms of TRPM7 modulation by these non-specific blockers are not clear. Although these are currently the best pharmacological tools available for studying TRPM7 functions, especially useful for the biophysical characterizations, finding and developing a specific pharmacological blocker would be the first priority in the road of targeting TRPM7 as a novel therapeutic approach for stroke.

Noticing the pressing needs for discovering selective pharmacological blockers, Castillo et al ${ }^{[68]}$ recently developed and optimized a Fura-2 based high-throughput screening (HTS) assay that can be used to narrow down the TRPM7 inhibitors. This bioassay utilizes HEK293 cells that have a tetracyclineinducible TRPM7 expression system. Compared to noninduced cells, induced TRPM7-HEK293 cells exhibit TRPM7mediated $\mathrm{Mn}^{2+}$ entry, which can be monitored by measuring the fluorescent quench of Fura-2 by $\mathrm{Mn}^{2+}$. Hence, using this bioassay, potential TRPM7 blockers would block TRPM7mediated $\mathrm{Mn}^{2+}$ entry and subsequently increase Fura-2 fluorescence. Instead of monitoring TRPM7-mediated $\mathrm{Ca}^{2+}$ entry, quenching of Fura-2 with the entry of $\mathrm{Mn}^{2+}$ was measured for 
the following reasons: (1) $\mathrm{Mn}^{2+}$ provides the largest quench of Fura-2 in TRPM7 overexpressing HEK293 cells; (2) TRPM7 is more permeable to $\mathrm{Mn}^{2+}$ than other competing channels, such as calcium-release activated calcium (CRAC) channels; and (3) the assay can be done in physiological levels of $\mathrm{Ca}^{2+}$ and $\mathrm{Mg}^{2+}$, unlike measuring $\mathrm{Ca}^{2+}$ influx, which normally requires $\mathrm{Ca}^{2+}$-deficient assay conditions for the optimal measurement. The assay conditions were carefully evaluated to achieve the most optimal, high reproducible 96-well plate HTS assay. For instance, when the optimized bioassay was used for two known non-selective TRPM7 inhibitors, $\mathrm{LaCl}_{3}$ and 2-APB, the potencies were comparable to the previous published data under the following conditions: (a) seeding cell density of 60000 cells/well, (b) Fura-2-AM (dye) loading concentration of $2 \mu \mathrm{mol} / \mathrm{L}$, (c) Fura-2-AM loading time of $60 \mathrm{~min}$, (d) $\mathrm{Mn}^{2+}$ (Fura-2 quenching agent) concentration of $10 \mathrm{mmol} / \mathrm{L}$, (e) MET (vehicle solvent) concentration of $1 \%$. So far, no study using this HTS bioassay to screen potential TRPM7 channel inhibitors has been published. Along with the known nonselective inhibitors, newly screened candidates may even help us understand molecular and/or structural characteristics to design specific inhibitors de novo ${ }^{[69]}$.

Once potential blockers are carefully screened/designed, preclinical experiments should be designed to follow recommendations for preclinical stroke drug development established by the Stroke Academic Industry Roundtable $(\mathrm{STAIR})^{[70,71]}$. In response to striking discrepancy of the results between animal stroke models and human clinical trials, the STAIR group gathered in the late 1990s and published a set of criteria that should be followed before advancing candidates into clinical trials. Although meeting these criteria does not guarantee clinical success, close adherence to these guidelines will help us reduce the likelihood of failure and improve the chance for successful clinical trials.

\section{Conclusions}

Contrary to initial expectations formed based on the early animal stroke models, solely blocking glutamate receptors seems to be insufficient to preserve neurons during ischemic stroke. Considerable knowledge is gained about the non-glutamate dependent mechanisms of ischemic neuronal death and the idea of targeting these novel pathways offers a glimpse of hope in rather disappointing neuroprotection research. With in vitro and in vivo validation of the pathological effects of TRPM7 in cerebral ischemia, TRPM7 seems to be a promising target for the future generation of neuroprotective approach. Although there is no selective antagonist available for TRPM7, it may be possible to find or design a selective TRPM7 inhibitor with a thorough screening for potential compounds. Once found, extensive preclinical studies that fully adhere to recommendations from STAIR committee should be conducted before moving towards clinical trials.

\section{Acknowledgements}

This work was supported by a Discovery Grant from Natural Sciences and Engineering Research Council of Canada to
Dr Hong-Shuo SUN. Christine You Jin BAE is a recipient of Ontario Graduate Scholarship.

\section{References}

1 Roger VL, Go AS, Lloyd-Jones DM, Benjamin EJ, Berry JD, Borden WB, et al. Heart disease and stroke statistics - 2012 update: a report from the American Heart Association. Circulation 2012; 125: e2220.

2 Goldstein LB, Bushnell CD, Adams RJ, Appel $\sqcup$, Braun LT, Chaturvedi $\mathrm{S}$, et al. Guidelines for the primary prevention of stroke: a guideline for healthcare professionals from the American Heart Association/ American Stroke Association. Stroke 2011; 42: 517-84.

3 Taylor TN, Davis PH, Torner JC, Holmes J, Meyer JW, Jacobson MF. Lifetime cost of stroke in the United States. Stroke 1996; 27: 145966.

4 Brown DL, Boden-Albala B, Langa KM, Lisabeth LD, Fair M, Smith MA, et al. Projected costs of ischemic stroke in the United States. Neurology 2006; 67: 1390-5.

5 Andersen KK, Olsen TS, Dehlendorff C, Kammersgaard LP. Hemorrhagic and ischemic strokes compared: stroke severity, mortality, and risk factors. Stroke 2009; 40: 2068-72.

6 Saver JL. Time is brain - quantified. Stroke 2006; 37: 263-6.

7 Adams HP Jr, del Zoppo G, Alberts MJ, Bhatt DL, Brass L, Furlan A, et al. Guidelines for the early management of adults with ischemic stroke: a guideline from the American heart association/American stroke association stroke council, clinical cardiology council, cardiovascular radiology and intervention council, and the atherosclerotic peripheral vascular disease and quality of care outcomes in research interdisciplinary working groups: the American Academy of Neurology affirms the value of this guideline as an educational tool for neurologists. Stroke 2007; 38: 1655-711.

8 Hacke W, Kaste M, Bluhmki E, Brozman M, Davalos A, Guidetti D, et al. Thrombolysis with alteplase 3 to 4.5 hours after acute ischemic stroke. N Engl J Med 2008; 359: 1317-29.

9 Marler JR, Goldstein LB. Medicine. Stroke - tPA and the clinic. Science 2003; 301: 1677.

10 Davis SM, Lees KR, Albers GW, Diener HC, Markabi S, Karlsson G, et al. Selfotel in acute ischemic stroke: possible neurotoxic effects of an NMDA antagonist. Stroke 2000; 31: 347-54.

11 Yepes M, Roussel BD, Ali C, Vivien D. Tissue-type plasminogen activator in the ischemic brain: more than a thrombolytic. Trends Neurosci 2009; 32: 48-55.

12 Tissue plasminogen activator for acute ischemic stroke. The national institute of neurological disorders and stroke rt-PA stroke study group. N Engl J Med 1995; 333: 1581-7.

13 Albers GW, Olivot JM. Intravenous alteplase for ischaemic stroke. Lancet 2007; 369: 249-50.

14 Lansberg MG, Bluhmki E, Thijs VN. Efficacy and safety of tissue plasminogen activator 3 to 4.5 hours after acute ischemic stroke: a metaanalysis. Stroke 2009; 40: 2438-41.

15 Alberts MJ, Bertels C, Dawson DV. An analysis of time of presentation after stroke. JAMA 1990; 263: 65-8.

16 Demaerschalk BM. Thrombolytic therapy for acute ischemic stroke: the likelihood of being helped versus harmed. Stroke 2007; 38: 2215-6.

17 O'Collins VE, Macleod MR, Donnan GA, Horky LL, van der Worp BH, Howells DW. 1,026 experimental treatments in acute stroke. Ann Neurol 2006; 59: 467-77.

18 Aarts MM, Tymianski M. TRPMs and neuronal cell death. Pflugers Arch 2005; 451: 243-9.

19 Aarts MM, Tymianski M. TRPM7 and ischemic CNS injury. Neuro- 
scientist 2005; 11: 116-23.

20 McNulty S, Fonfria E. The role of TRPM channels in cell death. Pflugers Arch 2005; 451: 235-42.

21 Sun HS, Jackson MF, Martin LJ, Jansen K, Teves L, Cui H, et al. Suppression of hippocampal TRPM7 protein prevents delayed neuronal death in brain ischemia. Nat Neurosci 2009; 12: 1300-7.

22 Aarts M, lihara K, Wei WL, Xiong ZG, Arundine M, Cerwinski W, et al. A key role for TRPM7 channels in anoxic neuronal death. Cell 2003; 115: 863-77.

23 Xiong ZG, Zhu XM, Chu XP, Minami M, Hey J, Wei WL, et al. Neuroprotection in ischemia: blocking calcium-permeable acid-sensing ion channels. Cell 2004; 118: 687-98.

24 Chu XP, Papasian CJ, Wang JQ, Xiong ZG. Modulation of acid-sensing ion channels: molecular mechanisms and therapeutic potential. Int J Physiol Pathophysiol Pharmacol 2011; 3: 288-309.

25 Xiong ZG, Chu XP, Simon RP. C $\mathrm{Ca}^{2+}$-permeable acid-sensing ion channels and ischemic brain injury. J Membr Biol 2006; 209: 59-68.

26 Liu HT, Tashmukhamedov BA, Inoue H, Okada Y, Sabirov RZ. Roles of two types of anion channels in glutamate release from mouse astrocytes under ischemic or osmotic stress. Glia 2006; 54: 343-57.

27 Oguro K, Jover T, Tanaka H, Lin Y, Kojima T, Oguro N, et al. Global ischemia-induced increases in the gap junctional proteins connexin 32 (Cx32) and $\mathrm{C} \times 36$ in hippocampus and enhanced vulnerability of Cx32 knock-out mice. J Neurosci 2001; 21: 7534-42.

28 de Pina-Benabou MH, Szostak V, Kyrozis A, Rempe D, Uziel D, UrbanMaldonado $\mathrm{M}$, et al. Blockade of gap junctions in vivo provides neuroprotection after perinatal global ischemia. Stroke 2005; 36: 2232-7.

29 Thompson RJ, Zhou N, MacVicar BA. Ischemia opens neuronal gap junction hemichannels. Science 2006; 312: 924-7.

30 Wang H, Zhang YL, Tang XC, Feng HS, Hu G. Targeting ischemic stroke with a novel opener of ATP-sensitive potassium channels in the brain. Mol Pharmacol 2004; 66: 1160-8.

31 Sun HS, Feng ZP, Miki T, Seino S, French RJ. Enhanced neuronal damage after ischemic insults in mice lacking Kir6.2-containing ATPsensitive $\mathrm{K}^{+}$channels. J Neurophysiol 2006; 95: 2590-601.

32 Sun HS, Feng ZP, Barber PA, Buchan AM, French RJ. Kir6.2-containing ATP-sensitive potassium channels protect cortical neurons from ischemic/anoxic injury in vitro and in vivo. Neuroscience 2007; 144: 1509-15.

33 Matsuda T, Arakawa N, Takuma K, Kishida Y, Kawasaki Y, Sakaue $\mathrm{M}$, et al. SEA0400, a novel and selective inhibitor of the $\mathrm{Na}^{+}-\mathrm{Ca}^{2+}$ exchanger, attenuates reperfusion injury in the in vitro and in vivo cerebral ischemic models. J Pharmacol Exp Ther 2001; 298: 24956.

34 Annunziato L, Pignataro G, Di Renzo GF. Pharmacology of brain $\mathrm{Na}^{+}$/ $\mathrm{Ca}^{2+}$ exchanger: from molecular biology to therapeutic perspectives. Pharmacol Rev 2004; 56: 633-54.

35 Pignataro G, Tortiglione A, Scorziello A, Giaccio L, Secondo A, Severino $B$, et al. Evidence for a protective role played by the $\mathrm{Na}^{+} / \mathrm{Ca}^{2+}$ exchanger in cerebral ischemia induced by middle cerebral artery occlusion in male rats. Neuropharmacology 2004; 46: 439-48.

36 Simard JM, Chen M, Tarasov KV, Bhatta S, Ivanova S, Melnitchenko L, et al. Newly expressed SUR1-regulated NC(Ca-ATP) channel mediates cerebral edema after ischemic stroke. Nat Med 2006; 12: 433-40.

37 Choi DW. Glutamate neurotoxicity and diseases of the nervous system. Neuron 1988; 1: 623-34.

38 MacDonald JF, Xiong ZG, Jackson MF. Paradox of $\mathrm{Ca}^{2+}$ signaling, cell death and stroke. Trends Neurosci 2006; 29: 75-81.

39 Margaill I, Parmentier S, Callebert J, Allix M, Boulu RG, Plotkine M. Short therapeutic window for MK-801 in transient focal cerebral ischemia in normotensive rats. J Cereb Blood Flow Metab 1996; 16:
107-13.

40 Steinberg GK, Panahian N, Perez-Pinzon MA, Sun GH, Modi MW, Sepinwall J. Narrow temporal therapeutic window for NMDA antagonist protection against focal cerebral ischaemia. Neurobiol Dis 1995; 2: 109-18.

41 Hardingham GE, Bading $H$. Synaptic versus extrasynaptic NMDA receptor signalling: implications for neurodegenerative disorders. Nat Rev Neurosci 2010; 11: 682-96.

42 Muir KW, Lees KR. Clinical experience with excitatory amino acid antagonist drugs. Stroke 1995; 26: 503-13.

43 Aarts M, Liu Y, Liu L, Besshoh S, Arundine M, Gurd JW, et al. Treatment of ischemic brain damage by perturbing NMDA receptor- PSD95 protein interactions. Science 2002; 298: 846-50.

44 Sun HS, Doucette TA, Liu Y, Fang Y, Teves L, Aarts M, et al. Effectiveness of PSD95 inhibitors in permanent and transient focal ischemia in the rat. Stroke 2008; 39: 2544-53.

45 Zhou L, Li F, Xu HB, Luo CX, Wu HY, Zhu MM, et al. Treatment of cerebral ischemia by disrupting ischemia-induced interaction of nNOS with PSD-95. Nat Med 2010; 16: 1439-43.

46 Besancon E, Guo S, Lok J, Tymianski M, Lo EH. Beyond NMDA and AMPA glutamate receptors: emerging mechanisms for ionic imbalance and cell death in stroke. Trends Pharmacol Sci 2008; 29: 268-75.

47 Wu LJ, Sweet TB, Clapham DE. International Union of Basic and Clinical Pharmacology. LXXVI. Current progress in the mammalian TRP ion channel family. Pharmacol Rev 2010; 62: 381-404.

48 Monteilh-Zoller MK, Hermosura MC, Nadler MJ, Scharenberg AM, Penner R, Fleig A. TRPM7 provides an ion channel mechanism for cellular entry of trace metal ions. J Gen Physiol 2003; 121: 49-60.

49 Yamaguchi H, Matsushita M, Nairn AC, Kuriyan J. Crystal structure of the atypical protein kinase domain of a TRP channel with phosphotransferase activity. Mol Cell 2001; 7: 1047-57.

50 Demeuse P, Penner R, Fleig A. TRPM7 channel is regulated by magnesium nucleotides via its kinase domain. J Gen Physiol 2006; 127: 421-34.

51 Dorovkov MV, Ryazanov AG. Phosphorylation of annexin I by TRPM7 channel-kinase. J Biol Chem 2004; 279: 50643-6.

52 Clark K, Langeslag M, van Leeuwen B, Ran L, Ryazanov AG, Figdor CG, et al. TRPM7, a novel regulator of actomyosin contractility and cell adhesion. EMBO J 2006; 25: 290-301.

53 Clark K, Middelbeek J, Dorovkov MV, Figdor CG, Ryazanov AG, Lasonder E, et al. The alpha-kinases TRPM6 and TRPM7, but not eEF-2 kinase, phosphorylate the assembly domain of myosin IIA, IIB and IIC. FEBS Lett 2008; 582: 2993-7.

54 Jin J, Desai BN, Navarro B, Donovan A, Andrews NC, Clapham DE. Deletion of Trpm 7 disrupts embryonic development and thymopoiesis without altering $\mathrm{Mg}^{2+}$ homeostasis. Science 2008; 322: 756-60.

55 Ryazanova LV, Rondon $\sqcup$, Zierler S, Hu Z, Galli J, Yamaguchi TP, et al. TRPM7 is essential for $\mathrm{Mg}^{(2+)}$ homeostasis in mammals. Nat Commun 2010; 1: 109.

56 Abed E, Moreau R. Importance of melastatin-like transient receptor potential 7 and cations (magnesium, calcium) in human osteoblastlike cell proliferation. Cell Prolif 2007; 40: 849-65.

57 Nadler MJ, Hermosura MC, Inabe K, Perraud AL, Zhu Q, Stokes AJ, et al. LTRPC7 is a Mg.ATP-regulated divalent cation channel required for cell viability. Nature 2001; 411: 590-5.

58 Runnels LW, Yue L, Clapham DE. TRP-PLIK, a bifunctional protein with kinase and ion channel activities. Science 2001; 291: 1043-7.

59 Wei WL, Sun HS, Olah ME, Sun X, Czerwinska E, Czerwinski W, et al. TRPM7 channels in hippocampal neurons detect levels of extracellular divalent cations. Proc Natl Acad Sci U S A 2007; 104: 16323-8.

60 Jiang J, Li M, Yue L. Potentiation of TRPM7 inward currents by 
protons. J Gen Physiol 2005; 126: 137-50.

61 Li M, Du J, Jiang J, Ratzan W, Su LT, Runnels LW, et al. Molecular determinants of $\mathrm{Mg}^{2+}$ and $\mathrm{Ca}^{2+}$ permeability and $\mathrm{pH}$ sensitivity in TRPM6 and TRPM7. J Biol Chem 2007; 282: 25817-30.

62 Lipski J, Park TI, Li D, Lee SC, Trevarton AJ, Chung KK, et al. Involvement of TRP-like channels in the acute ischemic response of hippocampal CA1 neurons in brain slices. Brain Res 2006; 1077: 187-99.

$63 \mathrm{Li} \mathrm{M}$, Jiang J, Yue L. Functional characterization of homo- and heteromeric channel kinases TRPM6 and TRPM7. J Gen Physiol 2006; 127: 525-37.

64 Chen HC, Xie J, Zhang Z, Su LT, Yue L, Runnels LW. Blockade of TRPM7 channel activity and cell death by inhibitors of 5-lipoxygenase. PLoS One 2010; 5: e11161.

65 Parnas M, Peters M, Dadon D, Lev S, Vertkin I, Slutsky I, et al. Carvacrol is a novel inhibitor of Drosophila TRPL and mammalian TRPM7 channels. Cell Calcium 2009; 45: 300-9.

66 Krapivinsky G, Mochida S, Krapivinsky L, Cibulsky SM, Clapham DE.
The TRPM7 ion channel functions in cholinergic synaptic vesicles and affects transmitter release. Neuron 2006; 52: 485-96.

$67 \mathrm{Xu} \mathrm{H}$, Delling M, Jun JC, Clapham DE. Oregano, thyme and clovederived flavors and skin sensitizers activate specific TRP channels. Nat Neurosci 2006; 9: 628-35.

68 Castillo B, Porzgen P, Penner R, Horgen FD, Fleig A. Development and optimization of a high-throughput bioassay for TRPM7 ion channel inhibitors. J Biomol Screen 2010; 15: 498-507.

69 Zheng C, Han L, Yap CW, Xie B, Chen Y. Progress and problems in the exploration of therapeutic targets. Drug Discov Today 2006; 11 : 412-20.

70 Fisher M, Feuerstein G, Howells DW, Hurn PD, Kent TA, Savitz SI, et al. Update of the stroke therapy academic industry roundtable preclinical recommendations. Stroke 2009; 40: 2244-50.

71 Recommendations for standards regarding preclinical neuroprotective and restorative drug development. Stroke 1999; 30: 2752-8. 